\title{
Responses of turf-forming algae to spatial variations in the deposition of sediments
}

\author{
Laura Airoldi ${ }^{1,2,}$, Massimiliano Virgilio ${ }^{1}$ \\ ${ }^{1}$ Dipartimento di Scienze dell'Uomo e dell'Ambiente, Università di Pisa, via A. Volta 6, I-56126 Pisa, Italy \\ ${ }^{2}$ Centre for Research on Ecological Impacts of Coastal Cities, Marine Ecology Laboratories A11, University of Sydney, \\ New South Wales 2006, Australia**
}

\begin{abstract}
Responses of a turf-forming, filamentous, algal assemblage to spatial variation in the deposition of sediments were investigated from September 1994 to September 1996 on a rocky subtidal reef south of Livorno (Mediterranean Sea). Large- and small-scale spatial differences in the amount and size of sediment settling on and accumulating in the turf were investigated over 1 yr in relation to meteorological conditions and to patterns of abundance of the turf. A multifactorial manipulation of the deposition of sediment was used to test the hypotheses that (1) different amounts and grain-sizes of settling material affect the cover and biomass of the filamentous algae, (2) any effects of sedimentation are independent of the stage of development of the turf and (3) patterns are consistent at different spatial scales, ranging from a few centimetres to several metres. During the investigation, the regime of sedimentation fluctuated greatly over time and among sites. The distribution of the turf across different sites was, however, not apparently related to large-scale variations in the deposition of sediment. Within sites, accumulation of sediment in the turf was patchy. The results of the experiment indicated that patchiness may affect the local biomass of established turf-forming algae, the abundance of which significantly decreased in quadrats which had higher deposition of sediments. On a scale of centimetres, high accumulation of sediment decreased variability of algal biomass within individual quadrats. The effects of sediment on biomass were also significantly influenced by the stage of development of the turf. No effects were observed on the cover of the filamentous algae. These results suggest that the responses of the turf to variations in the characteristics of the depositional environment may vary with changes in spatial scale and may be dependent on the concomitant action of other physical and biological factors.
\end{abstract}

KEY WORDS: Pelagic-benthic coupling · Sedimentation - Spatial variability Experimental scale Colonisation Algal turf - Polysiphonia setacea - Rocky subtidal shore

\section{INTRODUCTION}

Evidence that benthic and pelagic habitats may be tightly linked biologically has increased in recent years (Menge et al. 1997 and references therein). Movement and deposition of particulate material are among the most important factors involved in these links (Airoldi et al. 1996). Spatial and temporal fluctuations in the quantity and quality of settling material, for example, have been shown to affect the structure, dis-

-E-mail: lairoldi@bio.usyd.edu.au

- Address for correspondence tribution and dynamics of seabed faunal communities (Moore 1972, Smetacek 1984, Graf 1987). Coupling between rates of sedimentation and the relative abundance of species has also been postulated for algal assemblages on temperate rocky shores (Littler et al. 1983, Stewart 1983, D'Antonio 1986, Airoldi et al. 1995). Stewart (1983) proposed that the seasonal changes in the abundance of some algae and the persistence of some perennial species dominating the vegetation on intertidal rocky platforms in Southern California, USA, were related to the presence and cyclical movement of sediment in the habitat. Littler et al. (1983) and McQuaid \& Dower (1990) suggested that spatial variability in the deposition of sediments may 
promote diversity on rocky shores by maintaining patchiness. They also hypothesised that the effects of deposition of sediment may be different if examined from the perspective of shores or microhabitats. So far, however, few experimental studies have been performed to investigate the role of sedimentation as a structuring factor in rocky shores (Kendrick 1991, Airoldi \& Cinelli 1997), and scarce quantitative information is available concerning the responses of algal assemblages to spatial and temporal variations in the characteristics of the depositional environment.

Macroalgal assemblages dominated by densely packed, turf-forming seaweeds are common in tropical and temperate intertidal and subtidal rocky shores (Dahl 1973, Lauret 1974, Hay 1981, Stewart 1982, Adey \& Goertmilier 1987, Underwood et al. 1991). Despite their abundance, turf-forming algae often are overlooked and the causes of their trend to monopolise space are still poorly known (Sousa et al. 1981, Airoldi in press). The prevalence of algal turfs has been attributed, among other factors, to their ability to accumulate large amounts of sediment (Sousa et al. 1981, Seapy \& Littler 1982, Stewart 1989). The dense network of ramifications within turfs forms a cohesive surface layer that tends to entrap particles moving on the bottom (Neumann et al. 1970, Scoffin 1970). This sediment is thought to interfere with the recruitment of algae that do not form turfs and with grazing by urchins and other herbivores, thus favouring spatial dominance by the turf (Sousa et al. 1981, D'Antonio 1986).

Sediment is considered to be a structural constituent of algal turfs (Stewart 1983, Kendrick 1991, Airoldi et al. 1995). This would suggest that the distribution and dynamics of these assemblages may be influenced by variations in the quantity and composition of settling material. Observations on turfs of filamentous algae were consistent with this model (Adey \& Goertmiller 1987, Kendrick 1991, Airoldi \& Cinelli 1997). Predictions of the effects of sedimentation on algal abundance, however, have been variable. Rates of colonisation of turfs in the Galapagos, for example, were negatively affected by high rates of sediment deposition, but effects on percentage cover did not result in a significant decrease of biomass (Kendrick 1991). Different patterns were suggested by Airoldi \& Cinelli $(1996,1997)$ for turfs in the Mediterranean, where low levels of deposition of sediment seemed to increase the biomass of algae but not their cover. The authors hypothesised that sediment deposition may differentially influence the horizontal (cover) and vertical (biomass) growth of the filamentous algae. Differences also seemed to occur between established turfs and turfs developing in patches of substratum cleared after a disturbance (Airoldi 1994), but patterns were not adequately quantified.
In this paper, we evaluate the response of a turfdominated macroalgal assemblage to spatial and temporal variations in the depositional environment. The study was done on a rocky subtidal reef south of Livorno, Italy (western Mediterranean Sea), which is characterised by turbid water and by an extensive abundance of filamentous, turf-forming algae (Airoldi et al. 1995, 1996). Large- (among sites) and small-scale (within sites) spatial differences in the amount and size of material settling on and accumulating in the turf were investigated over $1 \mathrm{yr}$ in relation to meteorological conditions and to patterns of abundance of turfforming algae. These observations provided the basis for subsequent experimental field work. A multifactorial experiment was designed to test (1) whether the deposition of different amounts and grain-sizes of sediment affects the cover and biomass of turf-forming algae, (2) whether any effects of sedimentation are independent of the stage of development of the turf and (3) whether patterns are consistent at different spatial scales, ranging from a few centimetres to several metres. In addition to turf-forming seaweeds, other species of algae were present in the study area. Specific experiments on the effects of sedimentation on these components of the assemblage and on their interactions with the turf have been reported elsewhere (Airoldi \& Cinelli 1997, Airoldi in press).

\section{MATERIALS AND METHODS}

Study site. The study was performed from September 1994 to September 1996 on an exposed rocky reef located approximately $10 \mathrm{~km}$ south of Livorno $\left(43^{\circ} 30^{\prime} \mathrm{N}, 10^{\circ} 20^{\prime} \mathrm{E}\right.$, Ligurian Sea) which extends about $300 \mathrm{~m}$ parallel to the shoreline at depths between 11 and $16 \mathrm{~m}$. The bottom is a wide, gently sloping sandstone platform that has eroded to form outcrops which support, on their upper surfaces, a dense filamentous turf consisting mostly of Polysiphonia setacea (Hollenberg) (Airoldi et al. 1995).

The area is characterised by moderately large loads of sediment, compared to other shallow coastal regions (Airoldi et al. 1996). The settling material consists primarily of terrigenous particles eroded by rainfall and of sediments resuspended by water turbulence (Airoldi et al. 1996). The particles sinking over the turf are, for the most part, inorganic; the organic material is generally highly degraded detritus. Detailed descriptions of the biochemical composition of settling material can be found in Airoldi et al. (1996).

During the first year of the study, average rainfall over the periods of deployment of the sediment traps was generally less than $2 \mathrm{~mm} \mathrm{~d}^{-1}$, with 1 exceptional peak in November (see Fig. 1A). Wind velocity from 
SE to NW (which is a good indicator of turbulence of water in the study area; authors' pers. obs.) was more variable over time (see Fig. 1A), and violent storms occurred during the winter months.

Depositional environment. The spatial and temporal variability of deposition of sediment over the algal turf was quantified by means of sediment traps. Two trap systems, each consisting of a set of 4 polypropylene cylindrical vessels, were placed in 2 sites, approximately $100 \mathrm{~m}$ apart, located at random within the study area at a depth of $14 \mathrm{~m}$. The vessels had an inner diameter of $51 \mathrm{~mm}$ and an aspect ratio of 3.9 in order to guarantee reliable results even in turbulent waters (Bloesch \& Burns 1980). They were held stable in vertical orientation by means of a stainless steel frame cemented to the bottom. The frame carried 2 opposite ' $\mathrm{T}$ ' arms, each ending with 2 fixed PVC cylinders (60 $\mathrm{mm}$ in diameter, $150 \mathrm{~mm}$ in height). The vessels were placed in the cylinders and held in position by rubber bands, with their mouths $50 \mathrm{~cm}$ above the seafloor. The traps were deployed on 9 accasions from September 1994 to September 1995 for periods of, on average, $34 \mathrm{~d}$, except for 1 period of $62 \mathrm{~d}$. Deployment and retrieval of the vessels were done by SCUBA diving. Vessels were closed with Parafilm and plastic stoppers before retrieval.

The material collected in each vessel was separated into a coarse fraction (retained on preweighed $200 \mu \mathrm{m}$ meshes) and a fine fraction (retained on ignited and preweighed GF/F glass microfiber filters). The abundance of each component was determined gravimetrically. The material was rinsed with distilled water to remove salts and dried to constant weight $\left(60^{\circ} \mathrm{C}\right.$ for $\left.24 \mathrm{~h}\right)$ before weighing on a Ohaus balance (mod. Galaxy TM100) to a precision of $10^{-4} \mathrm{~g}$ in the presence of silica gel. The average deposition of sediment per day over the algal turf was then calculated as the sum of weights of the coarse and fine fractions per unit area divided by the number of days of exposure of the traps.

Data were analysed using a 2-way model of analysis of variance (ANOVA) with time (9 levels) and site ( 2 levels) as random variables. Because some vessels were lost on a few occasions (but never more than 1 from each set of traps), random vessels were eliminated from the other sets to balance the number of replicate vessels within each location to 3 for each sampling period. Since vessels were attached to the same frame, we may not exclude the possibility that fluxes measured by replicate traps in each location were non-independent. If some positive correlation occurred, the outcome of the statistical tests involving site as a main factor or in an interaction with time might have been affected by increased probability of Type I error (Underwood 1997).
In this and in the following experiments, before running the analysis, the assumption of homogeneity of variances was examined using Cochran's $C$-test. Transformations of the data were done to stabilise variances when necessary

Abundance of the turf and trapped sediment. Spatial and temporal variations in the coverage and biomass of turf-forming algae and in the amount of trapped sediment were investigated from October 1994 to September 1995 at 3 permanent sites, of $30 \times 20 \mathrm{~m}$, randomly placed in the study area 60 to $100 \mathrm{~m}$ apart.

The percentage cover of the turf was estimated on 10 occasions in 4 replicate quadrats of $10 \times 10 \mathrm{~cm}$ selected at random on each sampling date at each site. When possible, sampling was done on the same day as sediment traps and samples for biomass were collected. Quadrats were sampled by means of the visual estimation method (Dethier et al. 1993, Benedetti-Cecchi et a1. 1996). A plastic grid with 25 small quadrats was used, and a score from 0 to $4 \%$ was given to the turf in each small quadrat. Percentage cover was analysed using a 2-way ANOVA, with time (10 levels) and site (3 levels) as random variables.

The biomass of turf-forming algae was estimated by destructively sampling portions of substratum $2 \times 2 \mathrm{~cm}$ in size that were totally covered by the turf. This allowed variations in the vertical growth of the turf to be separated from variations in its horizontal cover. Thickness was not measured directly because the turf is too soft, thus affecting the reliability of the measures. The turf was manually removed with tweezers from 4 quadrats randomly placed in each site and preserved in small plastic jars. Sampling was repeated each time the traps were retrieved for a total of 9 sampling times. Each time, all 3 sites were sampled during the same dive.

In the laboratory, the sediment accumulated into the turf was carefully washed away with distilled water and used for further analyses (see below). Coarse particles remaining in the turf were manually removed under a dissecting microscope. Turf-forming algae were decalcified in $5 \% \mathrm{HCl}$ to eliminate any calcareous residues, and their biomass was measured as dry weight $\left(60^{\circ} \mathrm{C}, 48 \mathrm{~h}\right)$ per unit area. Data were analysed by using a 2 -way ANOVA with time conly 8 levels because the data from the first sampling time were accidentally lost) and site (3 levels) as random factors.

The sediment removed from the turf was used to quantify the amount of sediment trapped in the filamentous mat. The coarse and fine fractions of sediment were separated and measured as described for sediment collected by traps. The amount of sediment was expressed as dry weight per unit area. The amounts of sediment trapped per unit biomass of the filamentous 
algae were also calculated and expressed as nondimensional ratios. Data were analysed using a 2-way ANOVA with time $(9$ levels for sediment per unit area and 8 levels for sediment per unit biomass of the turf) and site ( 3 levels) as random factors. Pooling procedures were used to increase the power of some of the tests (Underwood 1997).

Experimental study. A field experiment was started in May 1996 in order to test the hypothesis that different amounts and grain-sizes of sediment affect the cover and the biomass of turf-forming algae. The effects of sediment deposition were examined in relation to the stage of development of the turf and over a range of spatial scales, varying from a few centimetres (distance among subsamples within quadrats) to several metres (distance among areas). The experiment was done during the summer, when the deposition and movement of sediment are generally small in the study area (Airoldi et al. 1996, this study, see 'Results'). Usual calm conditions of the sea during this period should have guaranteed that sediment added to the plots was not removed by turbulence of water, but a series of anomalous storms probabiy reduced the effectiveness of the manipulation (see 'Discussion').

Fourteen areas of $2 \times 3 \mathrm{~m}$ were established along each side of a $30 \mathrm{~m}$ long transect at a depth of about $11 \mathrm{~m}$, and 2 areas were assigned at random to each treatment. Treatments were: (1) deposition of sediment unmanipulated; deposition of sediment enhanced by $100 \mathrm{~g} \mathrm{~m}^{-2} \mathrm{~d}^{-1}$ by addition of (2) fine sand, (3) medium sand and (4) coarse sand; deposition of sediment enhanced by $200 \mathrm{~g} \mathrm{~m}^{-2} \mathrm{~d}^{-1}$ by addition of (5) fine sand, (6) medium sand and (7) coarse sand. Six experimental quadrats of $7.5 \times 7.5 \mathrm{~cm}$ were randomly placed on the horizontal top surfaces of an equal number of rocky outcrops in each area and permanently marked at their edges with epoxy putty. To test the hypothesis that the effects of sediment deposition are independent of the stage of development of the turf, at the beginning of the experiment 3 of the 6 quadrats in each area were scraped completely clean of the resident organisms using a hammer and chisel, allowing colonisation of a young turf. Established turf was left undisturbed in the other 3 quadrats.

The sediment used to manipulate deposition of sediment was taken from a nearby shore, sieved through a series of screens with different mesh sizes, in order to separate fine sand (grain-size between 0.125 and $0.25 \mathrm{~mm}$ ), medium sand (grain-size between 0.25 and $0.5 \mathrm{~mm}$ ) and coarse sand (grain-size between 0.5 and $0.1 \mathrm{~mm}$ ) (Gray 1981), and dried to constant weights. Known amounts of sediment (5.6 or $11.2 \mathrm{~g}$ dry $w \mathrm{t}$ ) of different grain-sizes were applied once every $10 \mathrm{~d}$ to the experimental quadrats in the appropriate treatment area in order to artificially enhance natural average deposition of sediment by 100 or $200 \mathrm{~g} \mathrm{~m}^{-2} \mathrm{~d}^{-1}$. Chronic rates of sedimentation greater that $100 \mathrm{~g} \mathrm{~m}^{-2} \mathrm{~d}^{-1}$ are considered highly stressful for organisms living in coral reefs (Rogers 1990), but little quantitative information is available for algal assemblages in temperate reefs.

The percentage cover and biomass of turf-forming algae were measured in scraped and undisturbed quadrats in September 1996, 4 mo after the beginning of the experiment. Percentage cover was estimated by sampling a surface of $6 \times 6 \mathrm{~cm}$ in the middle of each quadrat, in order to avoid edge effects. Sampling was done using the visual estimation method. Three subsamples were then collected at random within each quadrat by driving a metal corer of $19 \mathrm{~mm}$ diameter through the turf and into the substratum, in order to quantify the biomass of turfforming algae. The samples were preserved in small plastic jars, and the biomass was measured in the laboratory as above.

The entire design for analysis of the data of percentage cover included, therefore, the following factors (Table 1): amount of sediment added $(0,100$ and $200 \mathrm{~g} \mathrm{~m}^{-2} \mathrm{~d}^{-1}$; fixed factor), grain-size of sediment (fine, medium and coarse; fixed factor), stage of

Table 1 Scheme of the sampling design used to investigate the effects of amount of sediment added $\left(\mathrm{g} \mathrm{m}^{-2} \mathrm{~d}^{-1}\right)$, grain-size of sediment, area (2 levels) and stage of development of the turf ( $D$ : developing, $E$ : established) on percentage cover of turf-forming algae. Each combination of factors was replicated in 3 quadrats. Three subsamples were collected within each quadrat for estimations of biomass

\begin{tabular}{|c|c|c|c|c|c|}
\hline Amount & Grain-size & Area & $\begin{array}{c}\text { Stage of } \\
\text { development }\end{array}$ & Quadrat & $\begin{array}{l}\text { Subsamples } \\
\text { (only for biomass) }\end{array}$ \\
\hline 0 & & 1 and 2 & $D$ and $E$ & 1.2 and 3 & 1,2 and 3 \\
\hline 0 & & 1 and 2 & $D$ and $E$ & 1,2 and 3 & 1. 2 and 3 \\
\hline 100 & Fine & 1 and 2 & $D$ and $E$ & 1,2 and 3 & 1,2 and 3 \\
\hline 100 & Fine & 1 and 2 & $D$ and $E$ & 1,2 and 3 & 1,2 and 3 \\
\hline 100 & Medium & 1 and 2 & $D$ and $E$ & 1,2 and 3 & 1.2 and 3 \\
\hline 100 & Medium & 1 and 2 & $D$ and $E$ & 1,2 and 3 & 1,2 and 3 \\
\hline 100 & Coarse & 1 and 2 & $D$ and $E$ & 1,2 and 3 & 1,2 and 3 \\
\hline 100 & Coarse & 1 and 2 & $D$ and $E$ & 1,2 and 3 & 1,2 and 3 \\
\hline 200 & Fine & 1 and 2 & $D$ and $E$ & 1,2 and 3 & 1,2 and 3 \\
\hline 200 & Fine & 1 and 2 & $D$ and $E$ & 1,2 and 3 & 1,2 and 3 \\
\hline 200 & Medium & 1 and 2 & $D$ and $E$ & 1,2 and 3 & 1,2 and 3 \\
\hline 200 & Medium & 1. and 2 & $D$ and $E$ & 1,2 and 3 & 1,2 and 3 \\
\hline 200 & Coarse & 1. and 2 & $D$ and $E$ & 1,2 and 3 & 1,2 and 3 \\
\hline 200 & Coarse & 1 and 2 & $D$ and $E$ & 1,2 and 3 & 1,2 and 3 \\
\hline
\end{tabular}


development of the turf (developing and established; fixed factor) and area (2 levels; random factor). Treatments with no additional sediment (controls) could not. have different grain-sizes; therefore grain-size was not completely orthogonal to amount of sediment added and the design was asymmetrical (Underwood 1997). Stage of development of the turf was orthogonal to all the other factors, while area was nested in the 7 combinations of amount of sediment added and grain-size.

Asymmetrical mixed-model ANOVA was used to determine differences between sediment treatments (amount of sediment and grain-size). The required sums of squares for the asymmetrical components of these analyses were calculated following Underwood $(1992,1993,1997)$. Two quadrats, 1 in each of 2 different treatments, were lost during the experiment. The missing data were replaced by the mean of the remaining 2 plots in each treatment, and the degrees of freedom were accordingly reduced (Underwood 1997).

The analysis of the data of biomass included quadrat (3 levels; random factor) as an additional factor nested in area (Table 1). The effects of sediment deposition on variability of biomass at a scale of centimetres were also examined. This was done by running an asymmetrical analysis using the variance of the data of biomass from the 3 replicated subsamples within each quadrat as the dependent variable. The design used for this analysis was the same as for cover. Student-NewmanKeuls (SNK) tests were used for a posteriori multiple comparisons of means.

\section{RESULTS}

\section{Deposition of sediment}

The average amount of material collected by sediment traps in the 2 sites varied from 2.1 to $28.2 \mathrm{~g}$ $\mathrm{m}^{-2} \mathrm{~d}^{-1}$ and from 2.2 to $177.9 \mathrm{~g} \mathrm{~m}^{-2} \mathrm{~d}^{-1}$ respectively (Fig, 1B). The large spatial differences observed were mostly related to the coarse fraction (Fig. 1C), while sedimentation of finer particles was less variable across sites (Fig. 1D). Sedimentation was generally greater during December-March, when wind velocity was high, which was probably related to resuspension of bottom sediments by wave action, rather than to contributions from erosion of terrestrial material due to rain. This is also suggested by the abundance of coarse material in the sediment traps. Temporal variation was much greater at one site than at the other, resulting in a significant interaction of Time $\times$ Site for all the components analysed (Total sediment: $F_{8,36}=10.56, \mathrm{p}<$ 0.001; Coarse material: $F_{8,36}=10.44, \mathrm{p}<0.001$; Fine material: $\left.F_{8,36}=3.59, \mathrm{p}<0.01\right)$.
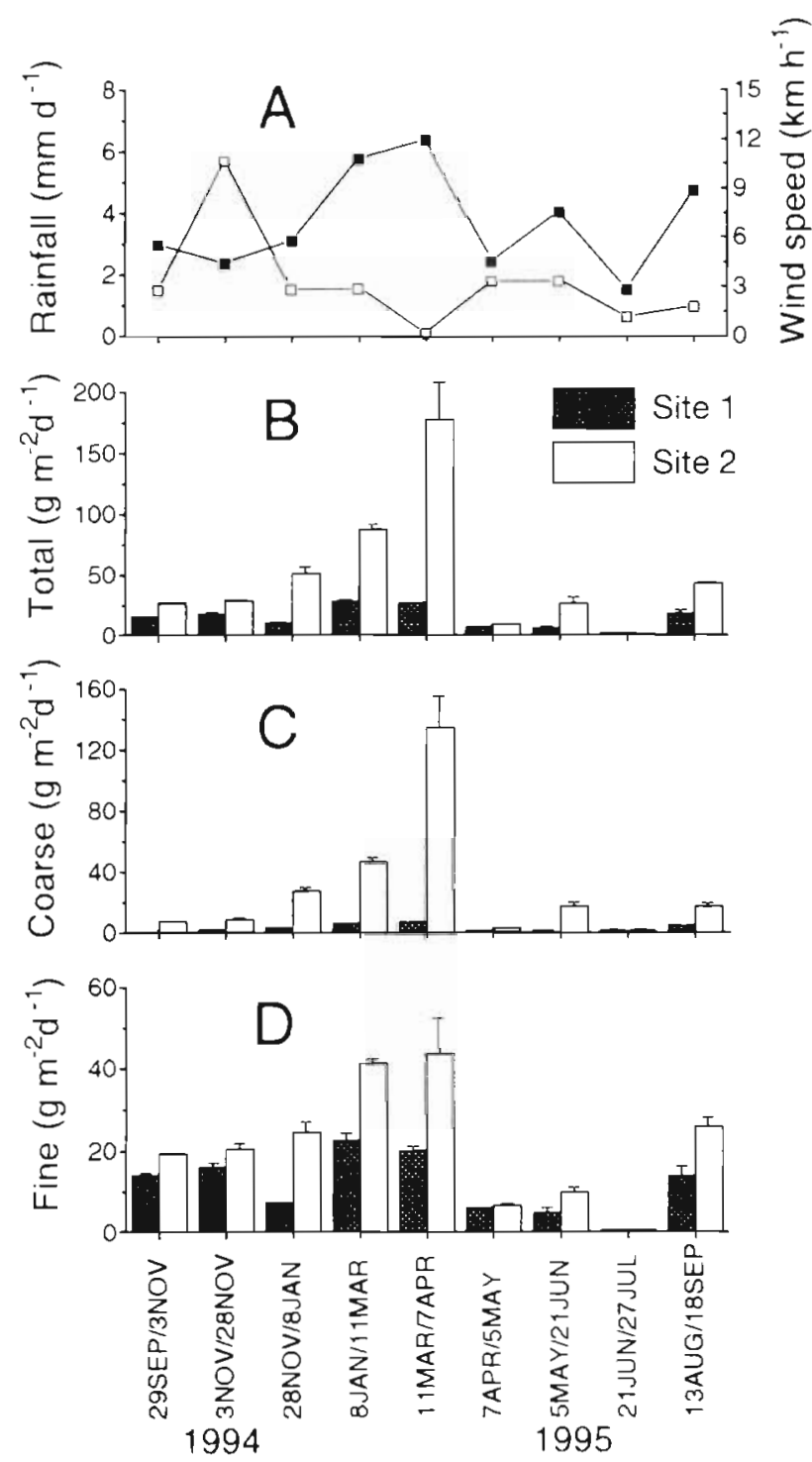

Fig. 1 (A) Mean rainfall () and wind speed from SE to NW $(\boldsymbol{m})$; and mean rates of deposition ( $\mathrm{SE}, \mathrm{n}=3$ ) of $(\mathrm{B})$ total sediment, (C) coarse material $(>200 \mu \mathrm{m})$ and (D) fine material $(<200 \mu \mathrm{m})$ at 2 sites during various periods of deployment of sediment traps from September 1994 to September 1995. Data for rainfall and wind speed were taken in the nearby city of Livorno; wind velocities were measured at 06:00 h

\section{Abundance of turf-forming algae and trapped sediment}

The average percentage cover of the turf was generally greater than $70 \%$ (Fig. 2). There was temporal variation (significant effect of Time, $F_{9,18}=2.55, \mathrm{p}<$ 0.05 ), with less cover in autumn and winter. This temporal trend was consistent at all sites (Time $\times$ Site interaction not significant, $F_{18,90}=0.86, \mathrm{p}>0.1$ ), and no significant differences were observed among sites $\left(F_{2,18}=1.13, \mathrm{p}>0.05\right)$. 


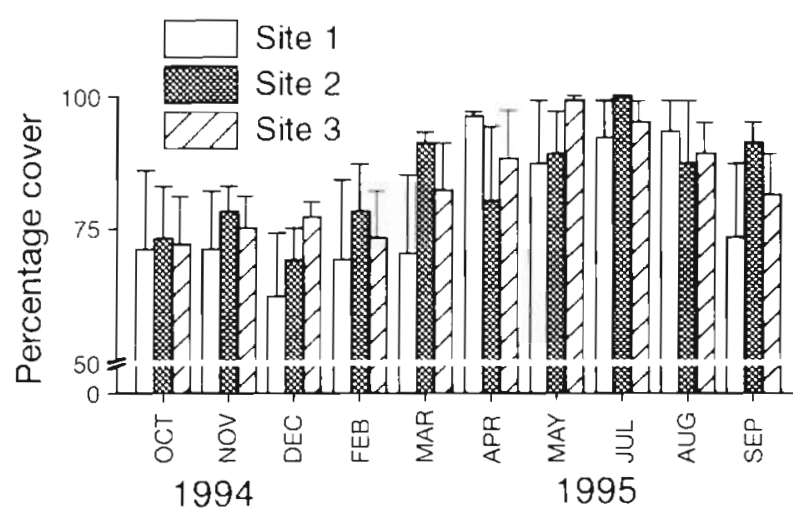

Fig. 2. Average ( $+\mathrm{SE}, \mathrm{n}=4$ ) percentage cover of filamentous turf at 3 sites from October 1994 to September 1995

Increasing abundance during summer was more pronounced for biomass at all sites (Fig. 3; significant effect of time, $F_{7.14}=11.57, \mathrm{p}<0.001$ ), reflecting large variations in the thickness of the turf. Mean biomass of filamentous algae varied from 7.8 to $120.1 \mathrm{~g} \mathrm{~m}^{-2}$. Biomass varied greatly among quadrats within sites, as suggested by large standard errors (Fig. 3), but, similar to percentage cover, no significant differences were observed among sites (Site: $F_{2,14}=2.18, \mathrm{p}>0.1$; Time $\times$ Site: $F_{14,72}=1.70, \mathrm{p}>0.05$ ).

The average amount of total sediment per unit area trapped within the filamentous turf varied from 86.4 to $923.6 \mathrm{~g} \mathrm{~m}^{-2}$ (Fig. 4). No significant temporal fluctuations were detected for any of the components analysed (Total sediment: $F_{8,16}=1.69, p>0.1$; Coarse material: $F_{8,16}=1.46, \mathrm{p}>0.1$; Fine material: $F_{8,16}=2.56$, $p>0.05$ ). The amount of sediment trapped varied greatly among quadrats (Fig. 4), and significant differences among sites were found for all the components of sediment (Total sediment: $F_{2,16}=5.10, \mathrm{p}<0.05$; Coarse material: $F_{2,16}=5.48, \mathrm{p}<0.05$; Fine material:

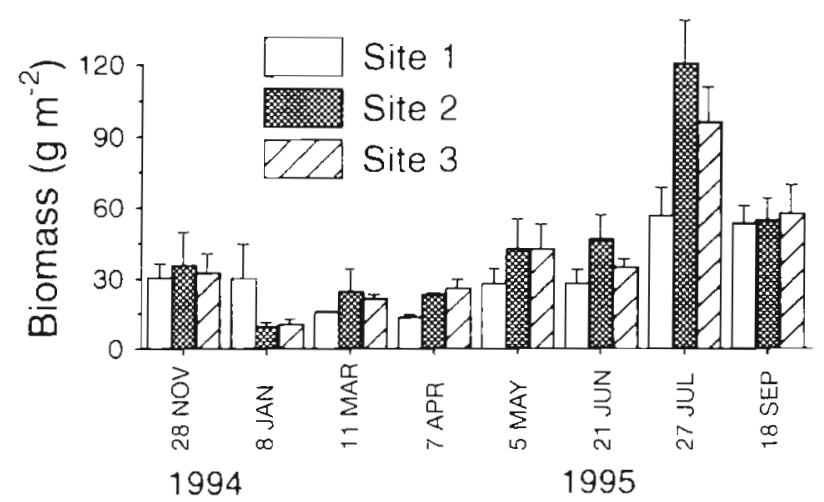

Fig. 3. Average (+SE, $n=4)$ biomass of filamentous algae at 3 sites from November 1994 to September 1995

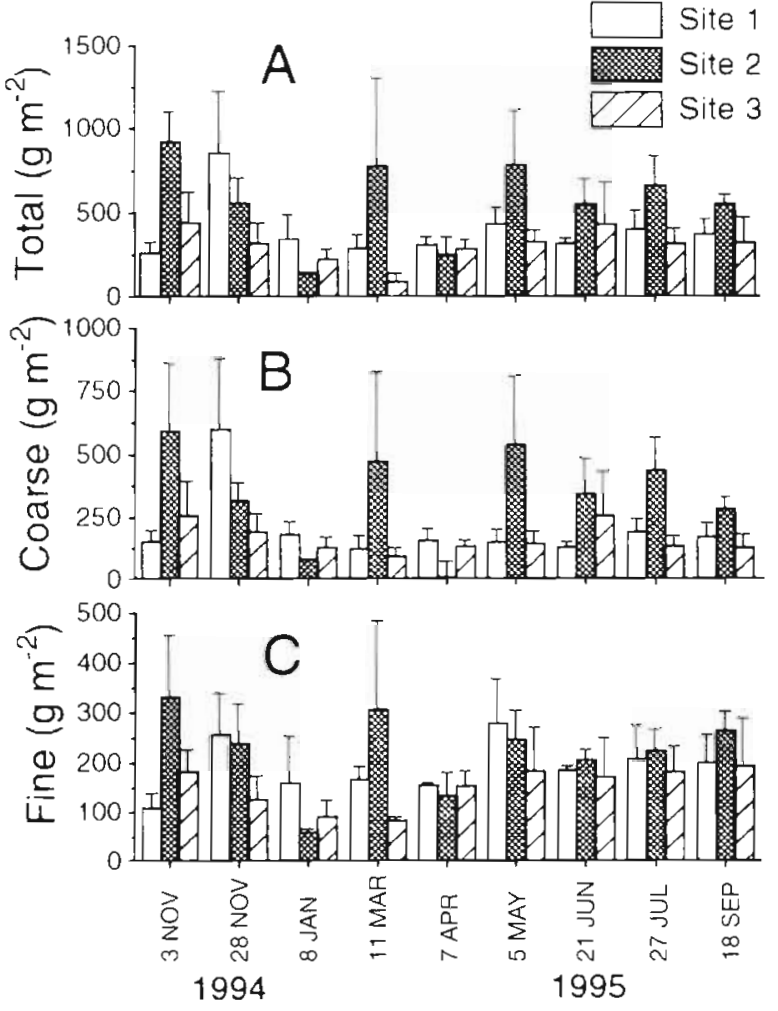

Fig. 4. Average ( $S E, n=4)$ weights of $(A)$ total sediment, (B) coarse material (>200 $\mu \mathrm{m}$ ) and (C) fine material (<200 $\mu \mathrm{m}$ ) trapped in the filamentous turf at 3 study sites from November 1994. to September 1995

$\left.F_{2,16}=3.95, \mathrm{p}<0.05\right)$. Time $\times$ Site interactions were not significant (Total sediment: $F_{1681}=1.03, \mathrm{p}>0.1$; Coarse material: $F_{16,81}=0.99, \mathrm{p}>0.1$; Fine material: $F_{16,81}=0.7, \mathrm{p}>0.1$.

The amount of trapped sediment was large compared to the biomass of the filamentous algae. The ratios between the amounts of total, coarse and fine sediments and the algal biomass reached average values up to 25, 18 and 13 respectively (Fig. 5). These ratios significantly fluctuated over time (Total sediment/algae: $F_{7,14}=5.76, \mathrm{p}<0.01 ;$ Coarse material/ algae: $F_{7,86}=2.86, \mathrm{p}<0.05$; Fine material/algae: $F_{7,14}=$ $4.79, p<0.01$ ), being greater during winter and spring at all sites. Ratios were variable among quadrats, and significant differences were detected among sites (Total sediment/algae: $F_{2,14}=7.02, \mathrm{p}<0.01$; Coarse material/ algae: $F_{2,86}=3.82, \mathrm{p}<0.05$; Fine material/algae: $F_{2,14}=$ $6.29, \mathrm{p}<0.05$ ). Time $\times$ Site interactions were not significant (Total sediment/algae: $F_{14,72}=1.03, \mathrm{p}>0.1$; Coarse material/algae: $F_{14.72}=1.26, \mathrm{p}>0.1$; Fine material/algae: $F_{14,72}=1.04, \mathrm{p}>0.1$ ). Overall, there was a significant negative relationship between the amount of trapped sediment and the biomass of turfforming algae (Fig. 6). 

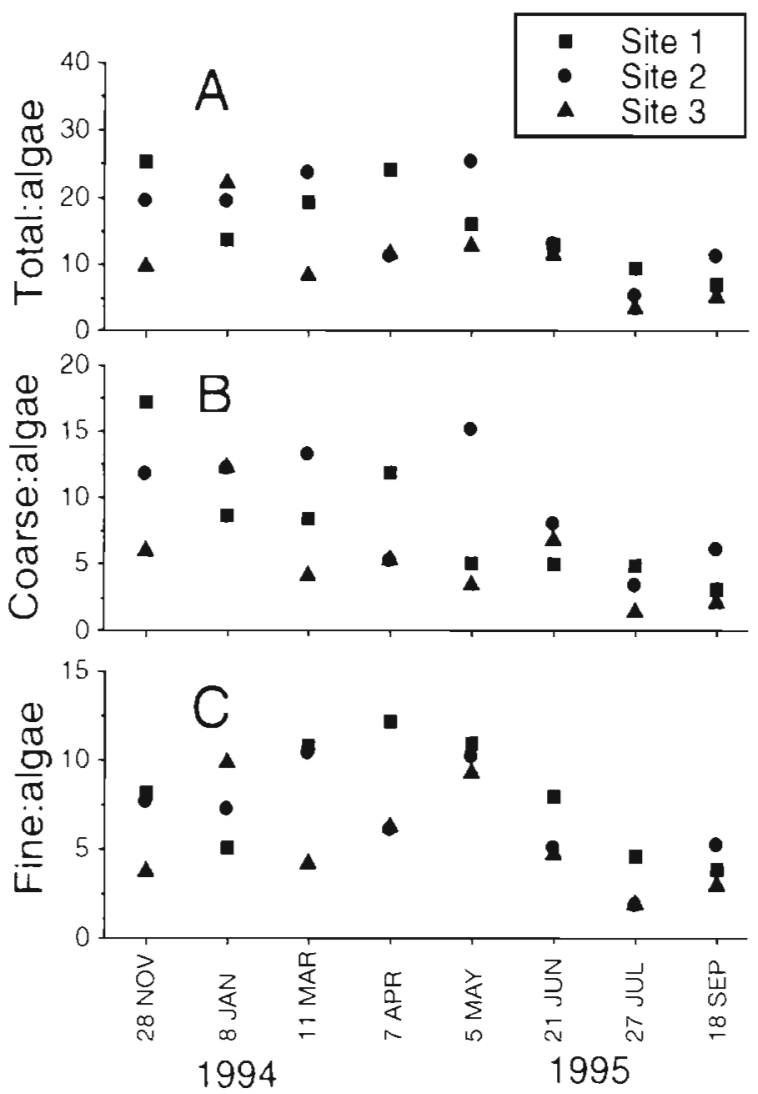

Fig. 5. Average $(n=4)$ ratios of (A) total sediment:algae, (B) coarse material:algae and (C) fine material:algae at 3 sites from November 1994 to September 1995. SE are not plotted for clarity

\section{Responses of the turf to variable deposition}

\section{of sediment}

Four months after the beginning of the experiment, the turf had completely regained space in scraped quadrats, reaching coverage comparable to that in undisturbed quadrats (Fig. 7), while restoration of a thick mat was not complete (Fig. 8). Patterns of recovery of the turf were variable in space, resulting in significant differences among areas (Tables $2 \& 3$ ) and among quadrats (Table 3 ).

Variations in the characteristics of the depositional environment did not affect the cover of the turf in scraped or undisturbed quadrats (Fig. 7, Table 2). Conversely, significant effects on the biomass of turf-

Fig. 7. Effects of varying addition and grain-size of sediment on the cover of (A) established and (B) developing turf in September 1996, 4 mo after the beginning of the experiment. Data are mean ( $\mathrm{SE}, \mathrm{n}=6$ ) percentage covers pooled across 2 areas
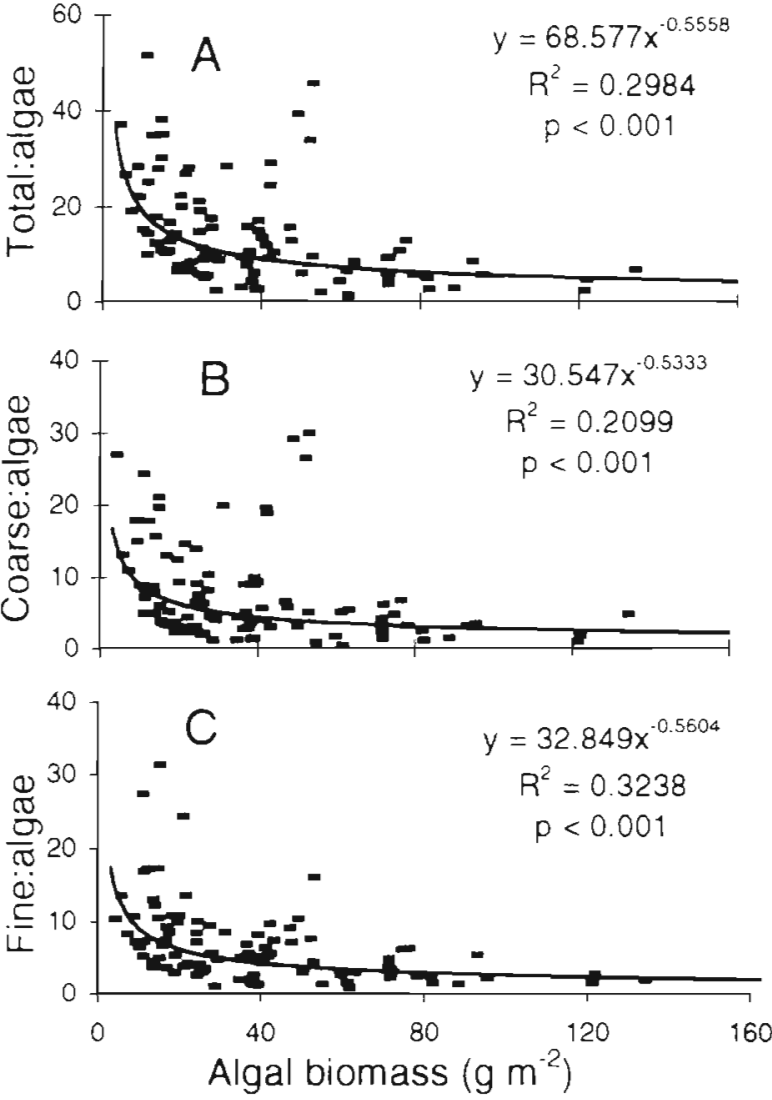

Fig. 6. Relationships between the ratios of (A) total sediment: algae, (B) coarse material:algae and (C) fine material:algae and the biomass of turf. Data are from 3 sites and 8 times

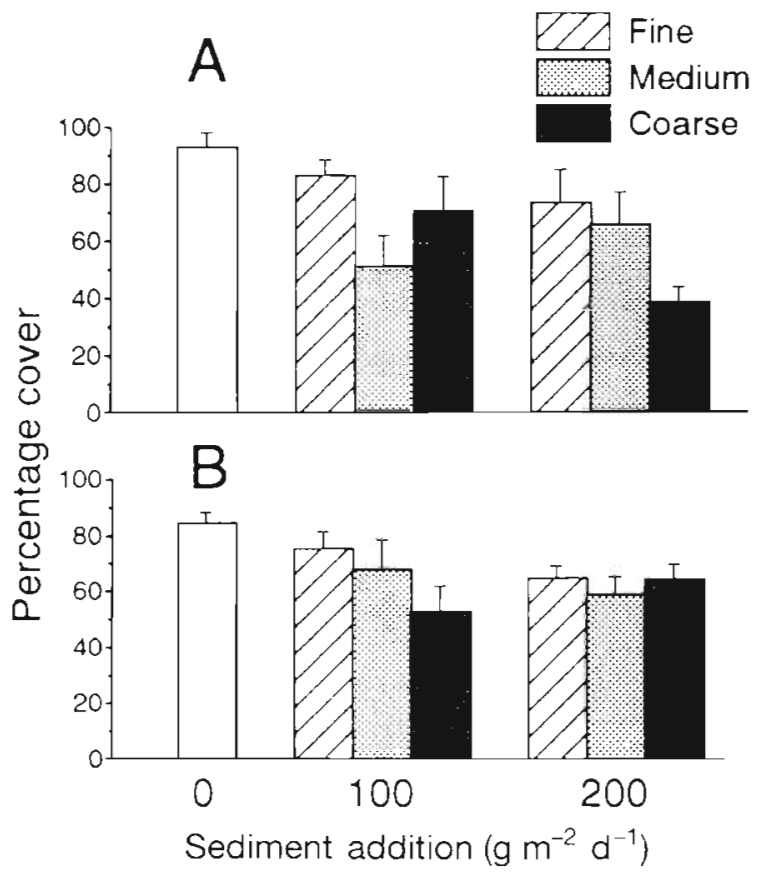




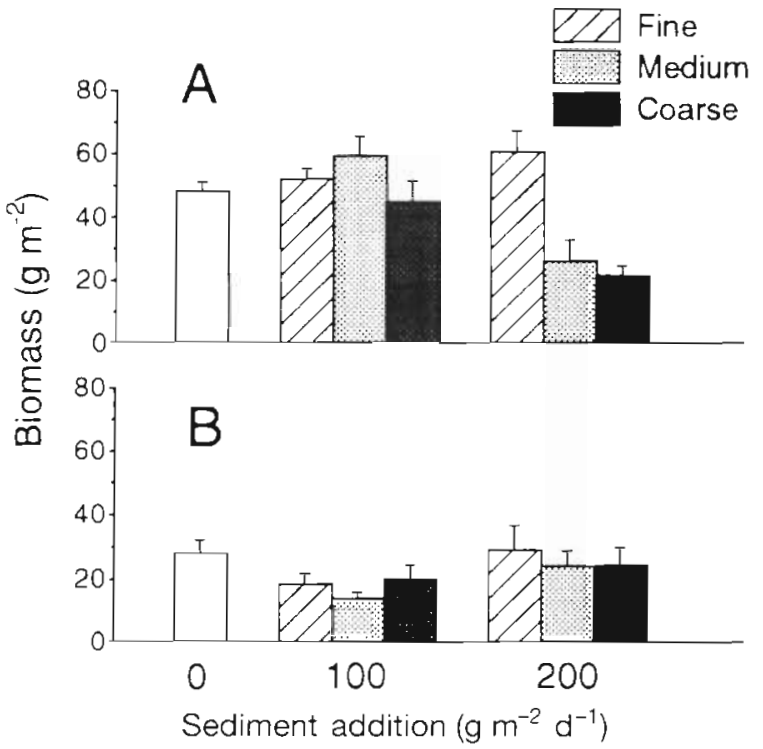

Fig. 8. Effects of varying addition and grain-size of sediment on the biomass of (A) established and (B) developing turf in September 1996, 4 mo after the beginning of the experiment. Data are mean $(+\mathrm{SE}, \mathrm{n}=6$ ) values of biomass pooled across

$$
2 \text { areas }
$$

forming algae were detected, but only in undisturbed quadrats with an established assemblage (Fig. 8, Table 3), resulting in a significant Stage $\times$ Amount interaction. In these treatments, the biomass of the filamentous algae significantly decreased in plots with higher rates of deposition of sediments. These effects were especially evident in plots where medium and

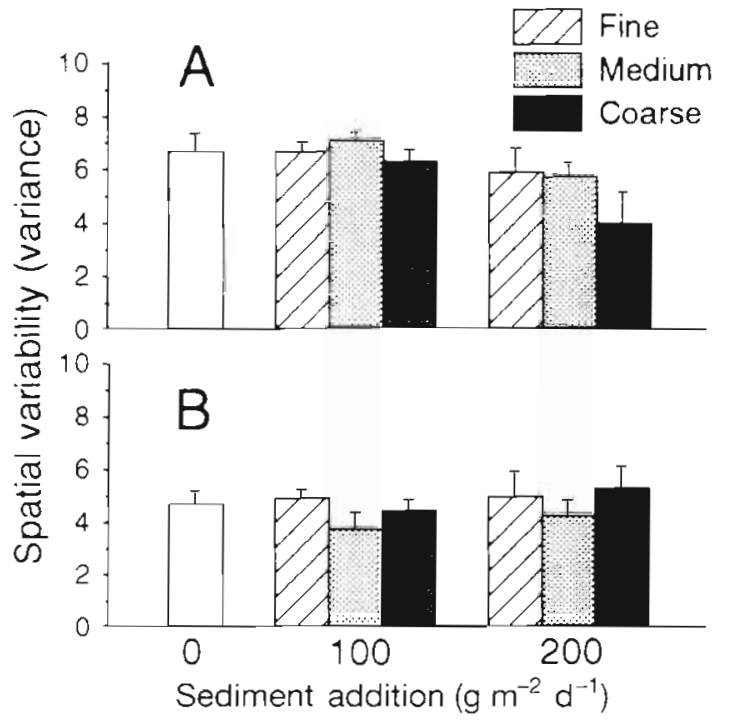

Fig. 9. Effects of varying addition and grain-size of sediment on small-scale spatial variability of algal biomass of (A) established and (B) developing turf in September 1996, 4 mo after the beginning of the experiment. Data are mean $(+\mathrm{SE}, \mathrm{n}=6)$ variances of values of biomass within each quadrat pooled across 2 areas

coarse material were added, but differences among grain-sizes were not statistically significant.

The amount and grain-size of sediment affected variability of biomass within individual quadrats, but only in undisturbed plots with an established assemblage, resulting in significant Stage $\times$ Amount and Stage $x$ Grain-size interactions (Fig. 9, Table 4). Higher levels

Table 2. Asymmetrical analysis of effects of variable amounts and grain-size of sediment on percentage cover of the filamentous turf. Factors are: amount of sediment added ( 0 vs $100 \mathrm{vs} 200 \mathrm{~g} \mathrm{~m}^{-2} \mathrm{~d}^{-1}$; fixed), grain-size (fine vs medium vs coarse; fixed), stage of development of the turf (developing vs established; fixed) and area (2 areas, nested in sediment treatments; random). For further details on the analysis see 'Material and methods' $\cdots p<0.01$

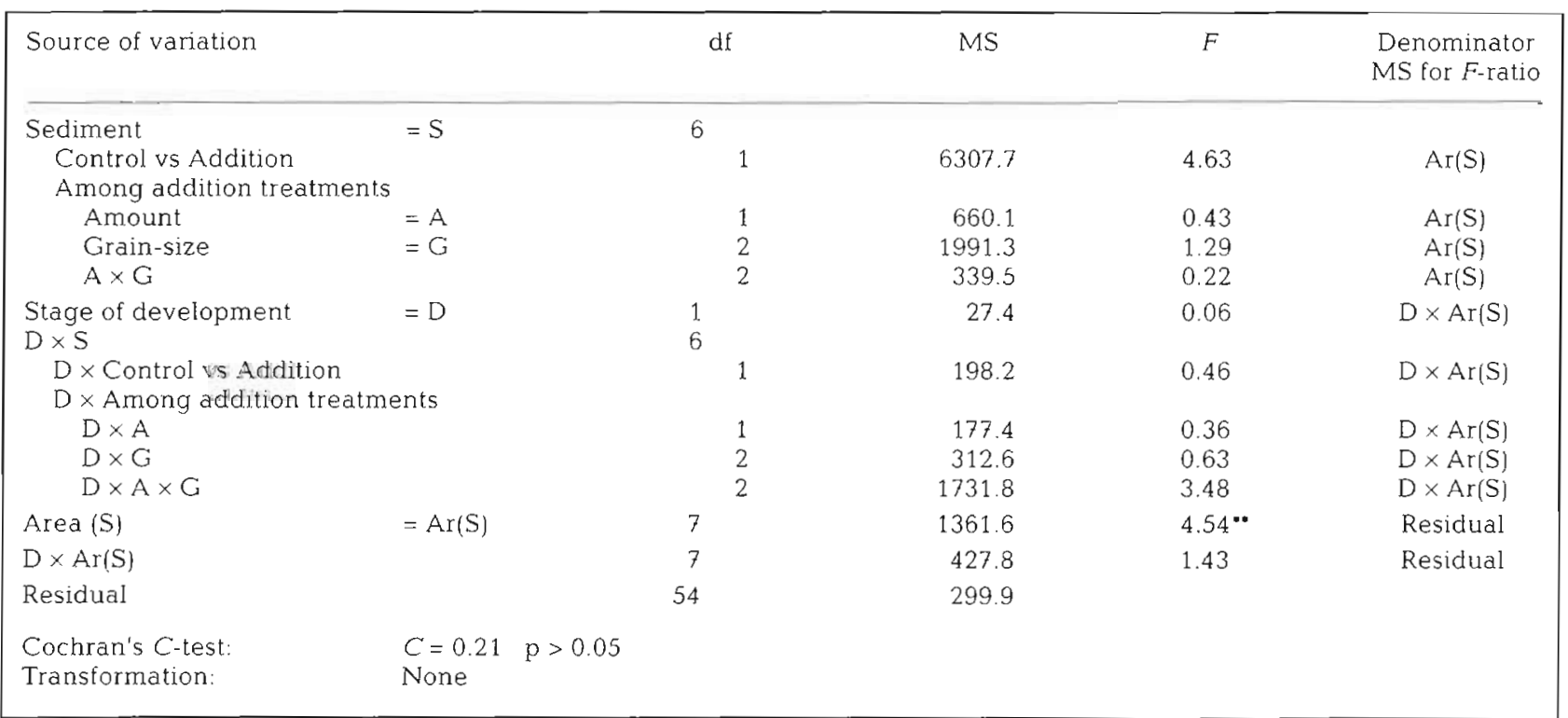


Table 3. Asymmetrical analysis of effects of variable amounts and grain-size of sediment on biomass of the filamentous algae. Factors are as in Table 2, and quadrat ( 3 quadrats, nested in area; random). For further details on the analysis see 'Material and methods' $\cdot p<0.05, \cdots p<0.01$

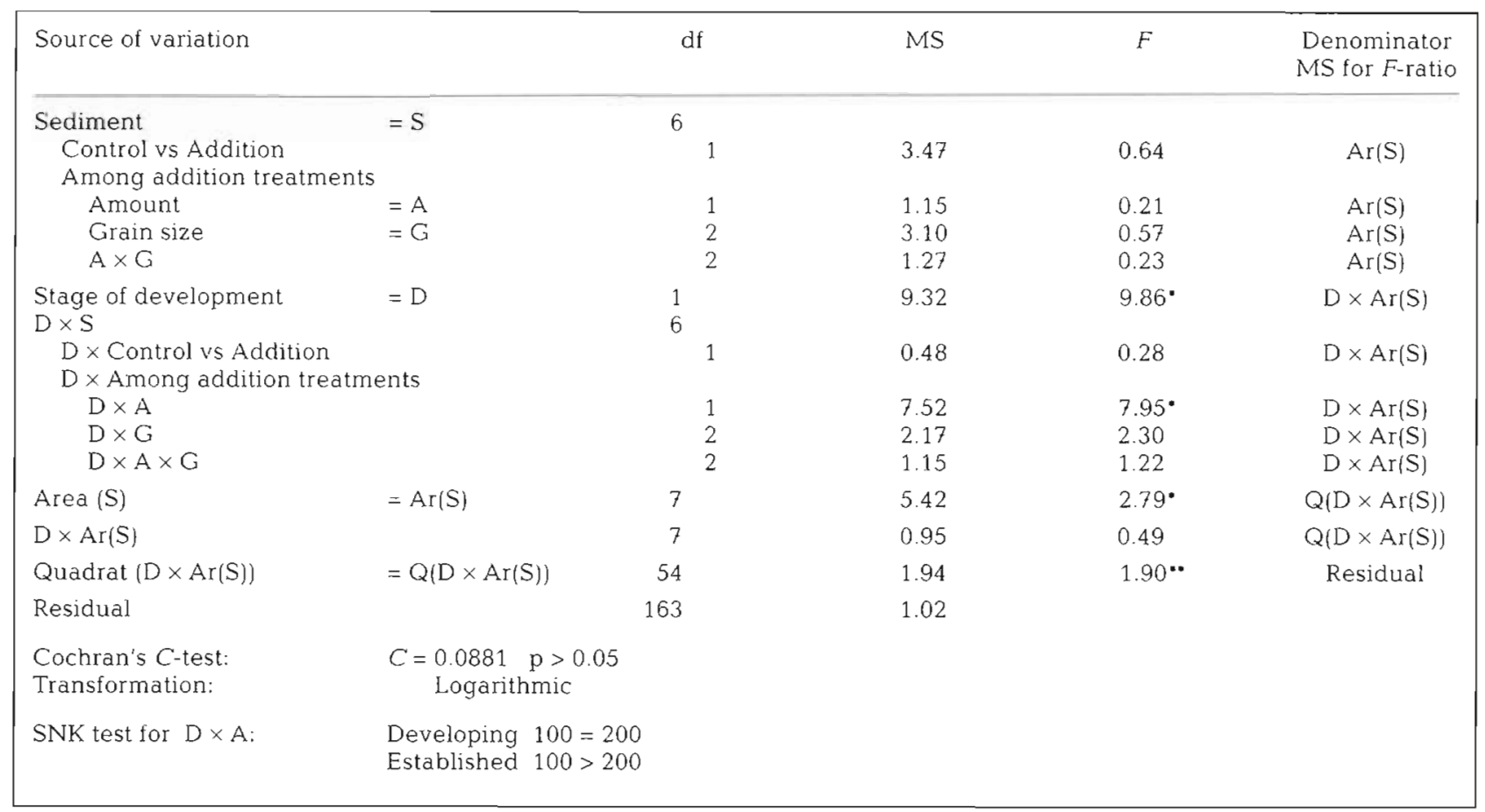

Table 4. Asymmetrical analysis of the effects of variable amounts and grain-size of sediment on small-5cale variability of biomass of the filamentous algae. Factors are as in Table 2. For further details on the analysis see 'Material and methods' $\cdot p<0.05$, $\cdots p<0.01, \cdots p<0.001$

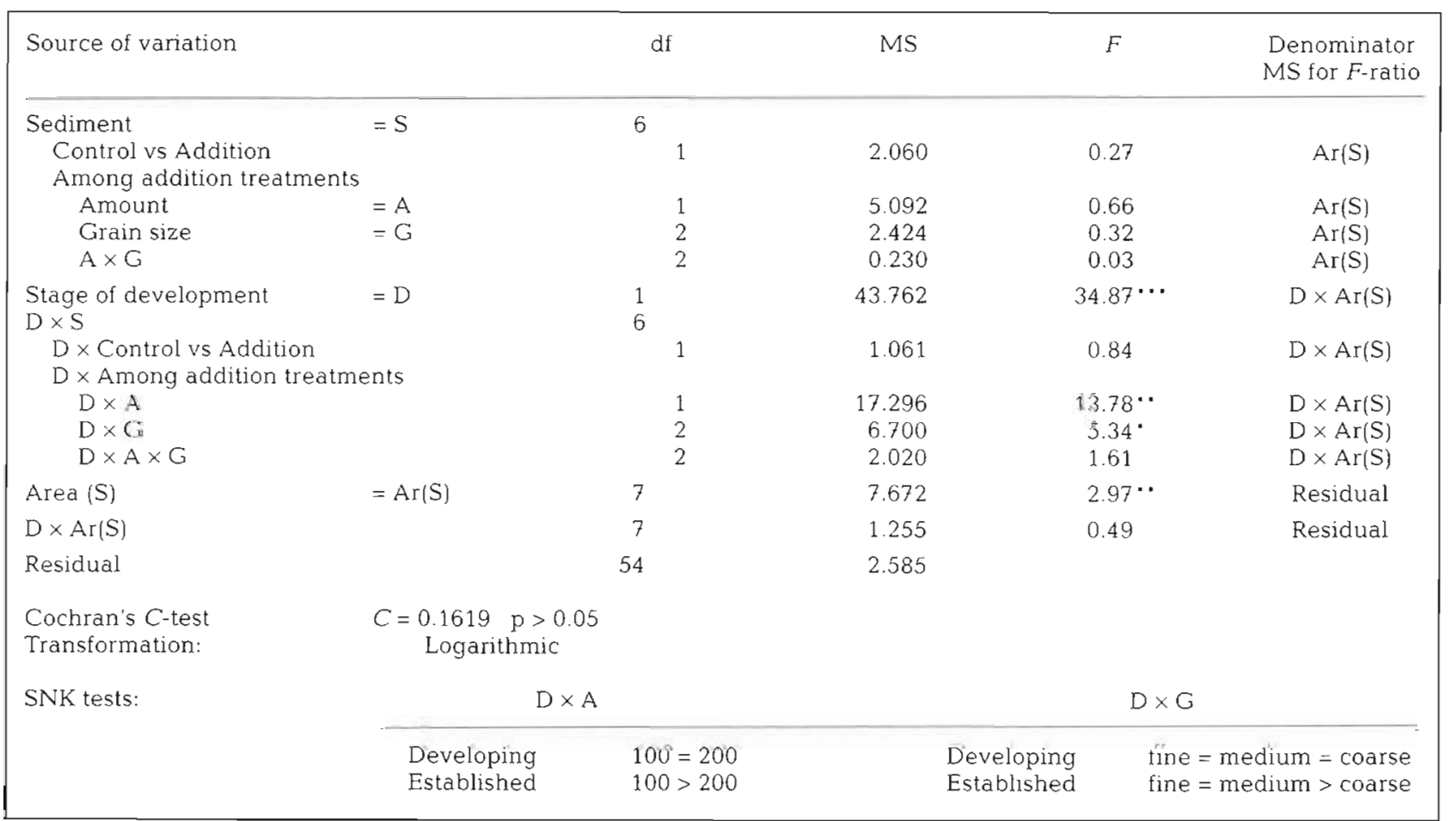


of sedimentation and the addition of coarse particles, in fact, significantly decreased variability in the biomass of the established turf (Table 4). No effects were observed on turf-forming algae developing in disturbed quadrats, where variability of biomass within quadrats was generally less than in the established assemblage.

\section{DISCUSSION}

Studies on coupling between sedimentation and the distribution of organisms on rocky shores have often emphasised temporal or large-scale spatial patterns (Daly \& Mathieson 1977, Seapy \& Littler 1982, Stewart 1983, Saiz Salinas \& Isasi Urdangarin 1994, Shaffer \& Parks 1994j. The prevalent opinion is that large loads of sediment are detrimental to the overall richness and diversity of assemblages on rocky shore. Recent studies, however, pointed out that, on a local scale biologically relevant to individual thalli or invertebrates, patterns of deposition may be highly variable, thus contributing to maintenance of small-scale heterogeneity of habitat (Littler et al. 1983, McQuaid \& Dower 1990, Trowbridge 1996). At a regional scale, the reef of this study is characterised by rates of sedimentation that are large compared to other shallow coastal areas (Airoldi et al. 1996 and references therein). The results, however, indicated that patterns of deposition of sediment may vary over different spatial scales. Sedimentation was greater following strong storms, and the regime of sedimentation significantly varied between nearby sites $100 \mathrm{~m}$ apart, suggesting an important role of the hydrodynamic conditions in influencing transport of sediment along the coast Superimposed on this large-scale pattern, sediment was redistributed within each site. At a scale of metres, accumulation of sediment in the turf was patchy, probably reflecting differences in the microtopography of the bottom and in profiles of flow speed at the boundary layer (Carpenter \& Williams 1993).

The biomass of the turf was apparently not related to variation in the amount of sediment deposition across different sites in the study area. At this spatial scale, the assemblage was strongly dominated by the algal turf (Airoldi et al. 1995, Airoldi in press). At a spatial scale of metres, however, algal biomass was negatively related to the amount of sediment trapped. Biomass of established algae differed significantly among experimental quadrats undergoing variable rates of deposition of sediment. Such variability has been shown to potentially influence the distribution and abundance of some erect species, which in the study area opportunistically exploit gaps of substratum relatively free of the turf (Airoldi \& Cinelli 1997, Airoldi in press). At a scale of metres, therefore, the patchiness of the depositional environment might locally enhance the diversity of the algal assemblage by mediating competitive interactions between the turf and the erect species. Conversely, on a scale of centimetres, large accumulation of sediment obscured differences in the biomass of the turf and decreased habitat variability within experimental quadrats.

These results support the hypothesis that the responses of algal assemblages to variations in the characteristics of the depositional environment may vary with changes in spatial scale (Littler et al. 1983, McQuaid \& Dower 1990). Thus, the perception of coupling between rates of sedimentation and the distribution and dynamics of aigal assemblages might be influenced by the spatial extent of a study. This is particularly important because the scales of most field experiments are usually relatively small, and it emphasises the need for caution when trying to predict patterns at spatial scales different from those directly investigated (Dayton \& Tegner 1984, Ricklefs 1987, Steel 1989, Jackson 1991, Levin 1992, Underwood \& Petraitis 1993).

Previous observations on the same assemblage suggested that smothering from sediments may affect the biomass of filamentous species developing in disturbed quadrats more than that of established adult turfs (Airoldi 1994), Opposite patterns were apparently indicated by the results of this experiment. Small-scale variations in the quantity and size of sediment significantly affected the biomass of turf-forming algae, but only in undisturbed quadrats with an established assemblage. A possible explanation for this unexpected outcome is that, during the experiment, some storms reduced the effectiveness of increased sedimentation by removing part of the sediment added to the plots (authors' pers. obs.). Removal of sediment by wave action was possibly more intense in scraped quadrats, where the turf was not thick enough to bind and stabilise sediments. Responses of colonising turfs to deposition could also be complicated by potential variation in their rates of growth related to time of the year when colonisation begins (Airoldi \& Cinelli 1997, Airoldi in press). Whatever the mechanism, the responses of turfforming algae to small-scale variations in the characteristics of the sedimentary environment were significantly influenced by their stage of development, and these effects were probably modulated by the concomitant action of other factors. Further experiments will be necessary to investigate if the effects of deposition of sediments on the algal assemblage are dependent on the regimes of disturbance and water movement of the area.

Sediment may be considered to be a structural constituent of this turf assemblage. The sediment trapped in the algal filaments represented, on average, $96 \%$ of 
the total mass of the turf. The amount of sediment per unit area remained relatively constant, despite significant temporal variations of rates of sedimentation. This suggests that the turf may trap particles and reduce their transport, thus stabilising sediments (Neumann et al. 1970, Scoffin 1970, Kendrick 1991). In turn, the characteristics of the depositional environment significantly affected the algal biomass, although the responses varied at different spatial scales and at different stages of development of the turf. Average rates of sedimentation greater than $200 \mathrm{~g} \mathrm{~m}^{-2} \mathrm{~d}^{-1}$ locally decreased the biomass of turf-forming algae in undisturbed plots, especially when associated with large grain-sizes. The vertical growth of the turf also seemed to be sensitive to scouring by sediments (Airoldi et al. 1995, Airoldi in press). Prostrate basal axes of the dominant species Polysiphonia setacea were, however, resistant to smothering and scouring (Airoldi in press), and the horizontal distribution of the turf in terms of cover was not affected by the characteristics of the depositional environment at any of the spatial scales examined in this and previous studies (Airoldi \& Cinelli 1996, 1997, Airoldi in press).

The interactions between algae and sediment within turfs are therefore complex and seem to be influenced by a number of factors acting at different spatial or temporal scales. It would appear that small-scale, detrimental effects on the vertical growth of the turf due to local accumulation of sediments might be compensated by indirect advantages for its horizontal distribution on larger spatial scales, possibly through limiting grazing by herbivores deterred by the presence of sediment (Robles 1982, D'Antonio 1986, McGuinness $1987 \mathrm{a}, \mathrm{b}$ ) or inhibiting recruitment by algae that do not form turfs (Sousa et al. 1981, Airoldi in press). Little experimental evidence actually supports these hypotheses, and further investigation is needed to evaluate the potential role of enhanced sediment loads in coastal areas in influencing spatial dominance by turfforming algae that do not form turfs (Airoldi in press). To make this evaluation, it will be important to understand the particular range of scales that are relevant to the ecological processes being examined, inciuding geographical differences in the regimes of physical and biological disturbance and local processes that influence spatial patchiness.

Acknowledgements. We wish to thank M. J. Anderson, L. Benedetti-Cecchi, M. G. Chapman, T. M. Glasby, G. A. Kendrick and A. J. Underwood for substantial revisions of the manuscript and input of ideas, and M. G. Chapman, M. Haddon and $A$. J. Underwood for advice with the statistical analyses. We are also grateful to $\mathrm{M}$. Abbiati and G. Caporali for their help in the field work. F. Cinelli and A. J. Underwood provided space and facilities at the Dipartimento di Scienze dell'Uomo e dell'Ambiente (Università di Pisa) and at the Centre for Research on Ecological impacts of Coastal Cities
(University of Sydney), respectively. This work was supported by a Postdoctoral Fellowship of the Università di Pisa and by a Postdoctoral Fellowship of the University of Sydney to L.A. (the latter while writing the paper). Daily precipitation rates and wind velocities were provided by the Ufficio Idrografico e Mareografico of Pisa and by the Avvisatore Marittimo of Livorno, respectively.

\section{LITERATURE CITED}

Adey WH, Goertmiller T (1987) Coral reef algal turfs: master producers in nutrient poor seas. Phycologia 26: 374-386

Airoldi L (1994) Studio sperimentale degli effetti della sedimentazione sullo sviluppo e sulla struttura di una comunità macroalgale bentonica infralitorale. PhD thesis, Università di Genova

Airoldi L (in press) Roles of variable disturbance, sediment stress and retention of substratum on spatial dominance in a subtidal algal turf. Ecology

Airoldi L, Cinelli F (1996) Early patterns of recovery of a filamentous algal turf on a rocky subtidal shore (Mediterranean Sea). Soc Ital Ecol Atti 17:341-344

Airoldi L, Cinelli F (1997) Effects of sedimentation on subtidal macroalgal assemblages: an experimental study from a Mediterranean rocky shore. J Exp Mar Biol Ecol 215: $269-288$

Airoldi L, Fabiano M, Cinelli F (1996) Sediment deposition and movement over a turf assemblage in a shallow rocky coastal area of the Ligurian Sea. Mar Ecol Prog Ser 133: 241-251

Airoldi L, Rindi F, Cinelli F (1995) Structure, seasonal dynamics and reproductive phenology of a filamentous turf assemblage on a sediment influenced, rocky subtidal shore. Bot Mar 38:227-237

Benedetti-Cecchi L, Airoldi L, Abbiati M, Cinelli F (1996) Estimating the abundance of benthic invertebrates: a comparison of procedures and variability between observers. Mar Ecol Prog Ser 138:93-101

Bloesch J, Burns NM (1980) A critical review of sedimentation trap technique. Schweiz Z Hydrol 42:15-55

Carpenter RC. Williams SL (1993) Effects of algal turf canopy height and microscale substratum topography on profiles of flow speed in a coral forereef environment. Limnol Oceanogr 38:687-694

Dahl AL (1973) Benthic algal ecology in a deep reef and sand habitat off Puerto Rico. Bot Mar 16:171-175

Daly MA, Mathieson AC (1977) The effect of sand movement on intertidal seaweeds and selected invertebrates at Bound Rock, New Hampshire, USA. Mar Biol 43:45-55

D'Antonio CM (1986) Role of sand in the domination of hard substrata by the intertidal alga Rhodomela larix. Mar Ecol Prog Ser 27:263-275

Dayton PK, Tegner MJ (1984) The importance of scale in community ecology: a kelp forest example with terrestrial analogs. In: Price PW, Slobodchikoff CN, Gaud WS (eds) A new ecology: novel approaches to interactive systems John Wiley and Sons, New York, p 457-481

Dethier MN, Graham ES, Cohen S, Tear LM (1993) Visual versus random-point percent cover estimations: 'objective is not always better. Mar Ecol Prog Ser 110:9-18

Graf G (1987) Benthic energy flow during a simulated autumn bloom sedimentation. Mar Ecol Prog Ser 39:23-29

Gray JS (1981) The ecology of marine sediments. Cambridge University Press, Cambridge

Hay ME (1981) The functional morphology of turf-forming 
seaweeds: persistence in stressful marine habitats Ecology 62:739-750

Jackson JBC (1991) Adaptation and diversity of reef corals. BioScience 41:475-482

Kendrick GA (1991) Recruitment of coralline crusts and filamentous turf algae in the Galapagos archipelago: effects of simulated scour, erosion and accretion. J Exp Mar Biol Ecol 147:47-63

Lauret M (1974) Etude phytosociologique préliminaire sur les gazons à Pterosiphonia pennata (Rhodophycées, Céramiales). Soc Phycol France Bull 19:229-237

Levin SA (1992) The problem of pattern and scale in ecology. Ecology 73:1943-1967

Littler MM, Martz DR, Littler DS (1983) Effects of recurrent sand deposition on rocky intertidal organisms: importance of substrate heterogeneity in a fluctuating environment. Mar Ecol Prog Ser 11:129-139

Menge BA, Daley BA, Wheeler PA, Strub PT (1997) Rocky intertidal oceanography: an association between community structure and nearshore phytoplankton concentrations. Limnol Oceanogr 42:57-66

McGuiness KA (1987a) Disturbance and organisms on boulders I. Patterns in the environment and the community. Oecologia 71:409-419

McGuiness KA (1987b) Disturbance and organisms on boulders II. Causes of patterns in diversity and abundance. Oecologia 71:420-430

McQuaid CD, Dower KM (1990) Enhancement of habitat heterogeneity and species richness on rocky shores inundated by sand. Oecologia 84:142-144

Moore PG (1972) Particulate matter in the sublittoral zone of an exposed coast and its ecological significance with special reference to fauna inhabiting kelp holdfast. J Exp Mar Biol Ecol 1.0:59-80

Neumann AC, Gebelein CD, Scoffin TP (1970) The composition, structure and erodability of subtidal mats, Abaco, Bahamas. J Sediment Petrol 40:274-297

Ricklefs RE (1987) Community diversity: relative roles of local and regional processes. Science 235:167-171

Robles C (1982) Disturbance and predation in an assemblage of herbivorous diptera and algae on rocky shores. Oecologia 54:23-31

Rogers CS (1990) Responses of coral reefs and reef organisms to sedimentation. Mar Ecol Prog Ser 62:185-202

Saiz Salinas JI, Isasi Urdangarin I (1994) Response of sublittoral hard substrate invertebrates to estuarine sedimentation in the outer harbour of Bilbao (N. Spain). PSZN I: Mar. Ecol 15:105-131

Editorial responsibility: Otto Kinne (Editor),

Oldendorf/Luhe, Germany
Scoffin TP (1970) The trapping and binding of subtidal carbonate sediments by marine vegetation in Bimini Lagoon, Bahamas. J Sediment Petrol 40:249-273

Seapy RR, Littler MM (1982) Population and species diversity fluctuations in a rocky intertidal community relative to severe aerial exposure and sediment burial. Mar Biol 71:87-96

Shaffer JA, Parks DS (1994) Seasonal variation in and observations of landslide impacts on the algal composition of a Puget Sound nearshore kelp forest. Bot Mar 37:315-323

Smetacek V (1984) The supply of food to the benthos. In: Fasham M.JR (ed) Flows of energy and materials in marine ecosystems. Theory and practice. Plenum Press, New York, p 517-547

Sousa WP, Schroeter SC, Gaines SD (1981) Latitudinal variation in intertidal community structure: the influence of grazing and vegetative propagation. Oecologia 48:297-307

Steel JH (1989) Discussion: scale and coupling in ecological systems. In: Roughgarden J, May RM, Levin S (eds) Perspectives in ecological theory. Princeton University Press, Princeton, NJ, p 177-180

Stewart JG (1982) Anchor species and epiphytes in intertidal algal turf. Pac Sci 36:45-59

Stewart JG (1983) Fluctuations in the quantity of sediments trapped among algal thalli on intertidal rock platforms in southern California. J Exp Mar Biol Ecol 73:205-211

Stewart JG (1989) Establishment, persistence and dominance of Corallina (Rhodophyta) in algal turf. J Phycol 25:436-446

Trowbridge CD (1996) Demography and phenology of the intertidal green alga Codium setchellii: the enigma of local scarcity on sand-influenced rocky shores. Mar Biol 127:341-351

Underwood AJ (1992) Beyond BACI: the detection of environmental impact on populations in the real but variable world. J Exp Mar Biol Ecol 161:145-178

Underwood AJ (1993) The mechanics of spatially replicated sampling programmes to detect environmental impacts in a variable world. Aust J Ecol 18:99-116

Underwood AJ (1997) Experiments in ecology. Their logical design and interpretation using analysis of variance. Cambridge University Press, Cambridge

Underwood A.J, Kingsford MJ, Andrew NL (1991) Patterns in shallow subtidal marine assemblages along the coast of New South Wales. Aust J Ecol 6:231-249

Underwood AJ, Petraitis PS (1993) Structure of intertidal assemblages in different locations: how can local processes be compared? In: Ricklefs $R$, Schluter $D$ (eds) Species diversity in ecological communities. University of Chicago Press, Chicago, p 39-51

Submitted: December 1, 1997; Accepted: March 2, 1998 Proofs received from author(s): April 15, 1998 